\title{
Characterization and 2D Self-Assembly of CdSe Quantum Dots at the Air-Water Interface
}

Kerim M. Gattás-Asfura, Celeste A. Constantine, Matthew J. Lynn, Daniel A. Thimann, Xiaojun Ji, and Roger M. Leblanc*

Department of Chemistry, University of Miami, Coral Gables, FL 33146, USA

*Corresponding Author. E-mail: rml@ miami.edu

\section{Supporting Information}

\section{Stability of ODT's Thiol Group Against Oxidation at the Air-Water Interface}

The surface pressure-area isotherm of 1-octadecanethiol (ODT) was acquired at three different sub-phases [Ar-flushed water, $\mathrm{O}_{2}$-flushed water, and $10^{-4} \mathrm{M}$ dithiothreitol (DTT) in Arflushed water] and storage time [freshly purchased and after 2 year storage of closed bottle under ambient conditions]. The results are shown in the figures below. 
1-Octadecanethiol (Fresh)

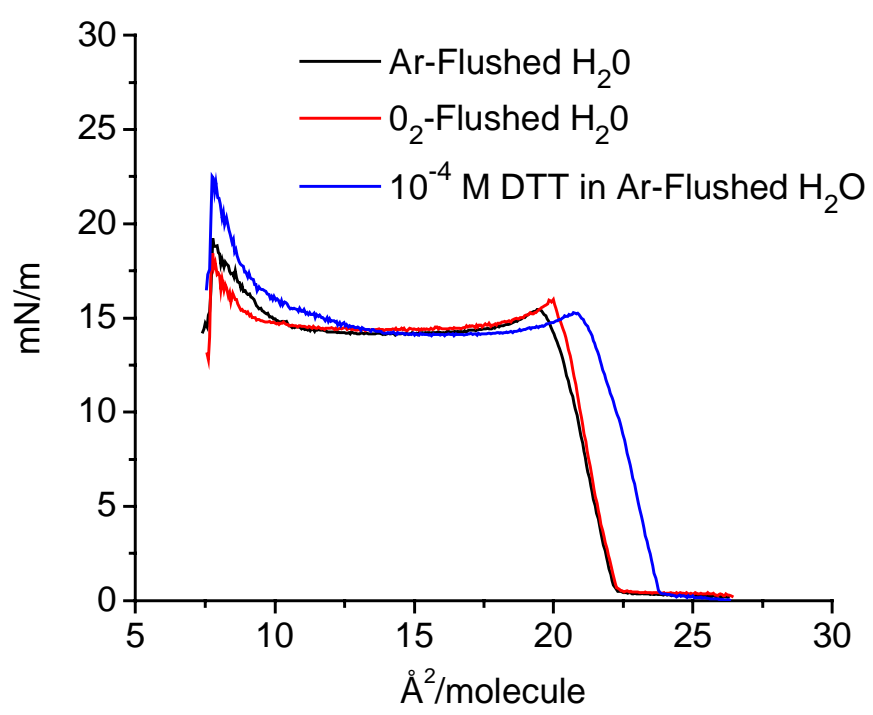

1-Octadecanethiol (after 2 year storage)

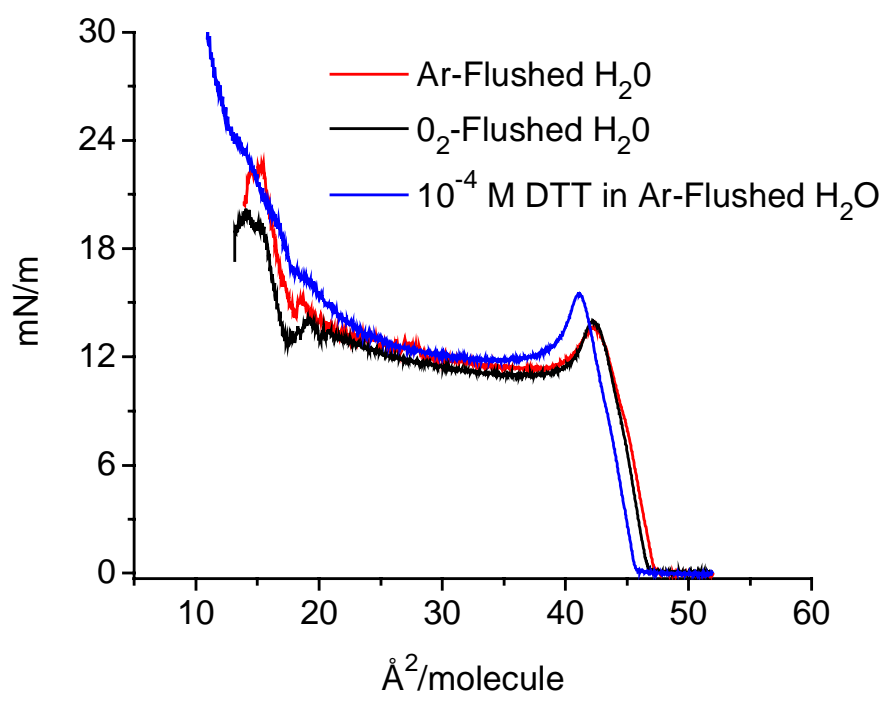


Even $\mathrm{O}_{2}$-flushed water or a DTT subphase resulted in no significant change in the isotherm or limiting molecular area of fresh ODT. This indicates that minimum or no oxidation takes place when utilizing fresh samples. DTT is used to reduce the disulfide bonds. No signs of oxidation could be detected unless the ODT is kept in a closed bottle under ambient conditions for long time and not protected with an Ar or a $\mathrm{N}_{2}$ atmosphere. The isotherm of ODT after stored for 2 years shifted significantly to a larger limiting area per molecule. This could clearly result from ODT's thiol group oxidation. Therefore, no or minimum oxidation of the thiol group of ODT at the air-water took place under the experimental conditions followed in this work. 